\title{
Cosmetic Surgery
}

National Cancer Institute

\section{Source}

National Cancer Institute. Cosmetic Surgery. NCI Thesaurus. Code C157741.

Procedures and techniques focused on improving an individual's appearance. 